\title{
LIFE: Recent Developments and Progress
}

T. M. Anklam

April 12, 2011 
This document was prepared as an account of work sponsored by an agency of the United States government. Neither the United States government nor Lawrence Livermore National Security, LLC, nor any of their employees makes any warranty, expressed or implied, or assumes any legal liability or responsibility for the accuracy, completeness, or usefulness of any information, apparatus, product, or process disclosed, or represents that its use would not infringe privately owned rights. Reference herein to any specific commercial product, process, or service by trade name, trademark, manufacturer, or otherwise does not necessarily constitute or imply its endorsement, recommendation, or favoring by the United States government or Lawrence Livermore National Security, LLC. The views and opinions of authors expressed herein do not necessarily state or reflect those of the United States government or Lawrence Livermore National Security, LLC, and shall not be used for advertising or product endorsement purposes.

This work performed under the auspices of the U.S. Department of Energy by Lawrence Livermore National Laboratory under Contract DE-AC52-07NA27344. 


\section{LIFE: Recent Developments and Progress}

\section{Progress on the National Ignition Facility}

Test results from the NIF show excellent progress toward achieving ignition. Experiments designed to verify coupling of the laser energy to the fusion target have shown that the efficiency meets that needed for ignition. Several tests with the cryogenic targets needed for ignition have been performed, and world-record neutron output produced. The National Ignition Campaign is on schedule to meet its 2012 ignition milestone, with the next phase in the campaign due to start later this month.

\section{External events}

The National Academies review of inertial fusion energy (IFE) is now in full swing. There have been a total of five meetings since December 2010: three with the full Committee and two with a panel dedicated to reviewing the anticipated performance of the fusion targets. The majority of these meetings have been dedicated to LIFE. Topics covered include our plant design, fusion physics basis and the delivery plan for the LIFE Plant. The committees have begun preparation of their first interim reports, scheduled to be released in the summer of 2011. A final report is due in the summer of 2012. The output is likely to advocate the need for public investment in IFE technology across a broad front.

A review of fusion under the auspices of the Electric Power Research Institute (EPRI) is planned to begin in June/July 2011. The emphasis of the EPRI review is on commercialization and delivery to market. This complements the National Academies review that is focused on the science and technology of IFE. The EPRI review will evaluate several proposed fusion technologies. Our understanding is that it will down-select to the most promising option(s) in Phase 1(this calendar year) and use this as the basis for developing a strategic business plan.

The second phase of the EPRI process will specify utility requirements for power production from fusion energy, along with the likely regulatory approach and address funding pathways and participation by the private and public sectors. The second phase is scheduled for completion by the end of 2012.

A high level workshop with the UK was held in Washington in February 2011. The UK Government's Chief Scientist opened the meeting, and called for a closely aligned approach to developing IFE. We are currently negotiating a memorandum of understanding with the UK to align our development and delivery efforts.

\section{LIFE Power Plant Design}

Good progress has been made with the LIFE power plant design. Some key design decisions have been made following guidance received in previous meetings with the utility and vendor industries. 
First, the pure fusion version of LIFE has been selected for delivery. While the fusion-fission hybrid has interesting mission potential, it is clear that the pure fusion option deserves highest priority as it has a clear pathway to market.

The second major decision was to adopt a commercially available super-critical Rankine cycle for the turbine island. Discussions with vendors indicated that the established Rankine technology is compatible with LIFE and has a competitive supply chain.

\section{Project Delivery}

A full work breakdown structure (WBS) has been derived based on a functional description of the power plant. This comprises 370 elements, and has been the basis for development of a detailed delivery plan for commercial electricity production.

The delivery plan covers the required construction, technology development, vendor facilitization and regulatory approvals activities. It contains 470 functional requirements and 970 work statements across 42 work packages. An integrated project schedule and cost estimate is in preparation. Delivery risk has been established using the accepted "Technology Readiness Level” approach developed by NASA and the DOD. This provides a quantitative assessment of residual risk as a function of project phase, geared around the key investment decisions that need to be made.

Over 30 vendors have been engaged to establish the performance and cost levels for key technologies, along with assessing the capacity and readiness to deliver of the supply chain. We have engaged major A\&E firms to assist in the development of the plant design, site and facility layouts and concept level cost estimates. Concepts of operations and maintenance have been developed alongside this process to inform the design.

\section{Licensing}

We have engaged experts in nuclear licensing to assess the likely framework for plant licensing. LIFE has a fundamentally different source term to fission reactors - only on when the lasers are operating. As such, a performance-based licensing approach, similar to that in Part 70 of existing NRC regulations, is appropriate - in contrast to the prescriptive Part 50/52 approach required for fission reactors. This approach will lead to a simplified licensing process with collateral benefits to construction costs and time-to-build. The route to developing this approach will be further advanced through the EPRI review process.

\section{Safety}

We have started the safety analysis of the plant design and performed an assessment of waste stream disposition. A preliminary set of reference accident sequences has been identified and accident consequence analysis has been conducted. As expected, the estimates of offsite dose consequences are fundamentally different to those associated with fission plants. This represents a key benefit of the LIFE design, and will be further quantified via Probabilistic Risk Assessments (PRA) in the near term. Waste stream assessments form the basis for materials specifications that ensure all waste streams are compatible with class-C shallow land burial or better. 


\section{LIFE Constituent Technologies}

Considerable progress is being made on the definition and demonstration of the constituent LIFE technologies:

- Targets: Procurement contracts are in preparation to begin fusion target massmanufacturing feasibility demonstrations. In-spec fuel capsules have been produced using a process scalable to mass manufacturing. Tests of these capsules are planned at the Omega laser facility this summer.

- Target Injector: A proof-of-concept target injector has been constructed. A target tracking system has been designed and is being fabricated. Testing is scheduled to begin this summer as part of a joint undertaking with General Atomics.

- Laser: The detailed design of the laser has been established and thoroughly reviewed by an independent expert committee earlier this year (chaired by Professor Byer from Stanford University). The design meets the Plant design requirements. A bill of materials for the system has been generated and is used as the basis for the system cost model. The laser system delivery plan has been developed based on extensive discussions with 14 semiconductor diode vendors and 6 optical component vendors. A joint LLNL/industry report on semiconductor diodes for LIFE was written and published, providing clear guidance on the consensus view of the industry in terms of laser performance, cost and capacity to deliver. These conclusions are fully consistent with our design requirements.

- Tritium Fuel Systems: A National Laboratory/University team has been assembled to develop the LIFE tritium processing system requirements. Participants include subject matter experts from the Princeton Plasma Physics Laboratory, Los Alamos National Laboratory, Savannah River National Laboratory and the University of California San Diego. The team is preparing requirements and specifications for the tritium system that will be used as the basis for procurement of industrial equipment. A workshop was held at LLNL in December 2010 to establish the design principles.

- Engine Materials: Collaboration with a steel production vendor yielded a test "lot" of low-impurity structural steel, as required for the fusion engine. This provides direct evidence for the waste stream and safety and performance assessments.

\section{Summary}

It has been a busy and very productive year. The NIF is in full 24/7 operations and has progressed markedly in the path toward ignition. The long-standing goal of the National Ignition Campaign to demonstrate ignition by the end of FY 2012 is on track. The LIFE plant design has matured considerably, and a delivery plan established based on close interactions with vendors. National-level reviews of fusion are underway, and are due to present initial findings later this year. A value proposition has been drafted for review. The LIFE project is ready to move into the delivery phase.

This work performed under the auspices of the U.S. Department of Energy by Lawrence Livermore National Laboratory under Contract DE-AC52-07NA27344. 